\title{
Effect of Angiotensin II-Induced Changes in Perfusion Flow Rate on Chlorothiazide Transport in the Isolated Perfused Rat Kidney
}

\author{
David E. Smith, ${ }^{1,2}$ Stephanie Guillard, ${ }^{1}$ and Carlos A. Rodríguez ${ }^{1}$ \\ Received June 10, 1991-Final March 2, 1992
}

\begin{abstract}
Angiotensin II was used as a probe to study the effect of changes in perfusate flow rate on the renal clearance parameters of chlorothiazide in the isolated perfused rat kidney. Perfusion studies were performed in five rats with no angiotensin II present in the perfusate and in five rats with a 1-4 $\mathrm{ng} / \mathrm{min}$ infusion of angiotensin II into the perfusate. Angiotensin II had a dramatic effect on the renal hemodynamics, resulting in a $43 \%$ decrease in perfusate flow, a $16 \%$ decrease in glomerular filtration rate (GFR), and a 45\% increase in filtration fraction. Values for the fractional excretion of glucose were low and consistent, with or without angiotensin II. Although the unbound fraction (fu) of chlorothiazide was unchanged between treatments, the renal $\left(\mathrm{CL}_{r}\right)$ and the secretion clearances were reduced by about $50 \%$ in the presence of angiotensin 17 ; the excretion ratio $\left[\mathrm{ER}=\mathrm{CL}_{r} /(\mathrm{fu} \cdot \mathrm{GFR})\right]$ was reduced by $38 \%$ with angiotensin II present in the perfusate. Analysis of the data was complicated by the presence of a capacity-limited transport for renal ubular secretion. Transport parameters $( \pm S D$ ) were obtained and the corrected intrinsic secretory clearance $\left[\left(\mathrm{V}_{\max } / \mathrm{GFR}\right) / \mathrm{K}_{m}\right]$ of chlorothiazide was $123 \pm 18$ without angiotensin II vs. $72.8 \pm 30.0$ with angiotensin II. These results demonstrate that alterations in organ perfusion can significantly reduce the clearance parameters of chlorothiazide in the rat IPK. These flow-induced changes in intrinsic secretory transport may reflect perturbations other than that of perfusion flow rate alone.
\end{abstract}

KEY WORDS: chlorothiazide; rat IPK; clearance parameters; perfusion flow rate.

\section{INTRODUCTION}

The kidney is a vital excretory organ in which glomerular filtration, proximal tubular secretion, and distal reabsorption serve to affect the irre-

\footnotetext{
This work was supported in part by the National Institutes of Health grant GM 35498. At the time of this study, S. Guillard was a pharmacy student of Xavier University of Louisiana participating in our Summer Undergraduate Research Program. During the course of this work, C. A. Rodriguez was supported by a Rackham Minority Merit Fellowship from The University of Michigan.

'College of Pharmacy, The University of Michigan, Ann Arbor, Michigan 48109-1065.

${ }^{2}$ To whom correspondence should be addressed.
} 
versible removal of drugs and metabolites from the body. Despite this complex relationship, theoretical models with experimental validation have emerged to better understand the effect of protein binding on renal drug transport, and in particular, active secretion (1-3). In contrast, few quantitative data are available on the effect of changes in renal blood flow on the tubular secretion of drugs $(4,5)$. As a result, the role of organ perfusion on renal drug extraction is conspicuously absent from the literature (6) or considered in a more descriptive manner (7).

In the present study, the effect of changes in organ perfusion rate on the renal clearance of a highly secreted drug was investigated, and the mechanisms by which flow-induced changes might occur. Chlorothiazide was chosen for study because it demonstrates a net active secretion from the renal tubules and is eliminated solely as unchanged drug by the renal route $(8,9)$. In addition, the interpretation of data from a previous study (10) concerning chlorothiazide transport in the isolated perfused rat kidney was complicated by perturbations in perfusate flow rate, the effect of which is not known. The isolated perfused rat kidney (rat IPK) was chosen as an experimental model because it allows for precise concentrations of drug and modulator to be presented to the kidney. Perfusate flow rate can also be measured directly with this technique, and experiments can be performed in the absence of complicating extrarenal factors (e.g., hormonal stimuli, peripheral tissue binding).

\section{METHODS}

\section{Perfusate}

The initial perfusate volume was $100 \mathrm{ml}$. It consisted of Krebs-Henseleit bicarbonate (KHB) buffer containing $6.00 \%$ bovine serum albumin (BSA) (Fraction V; ICN ImmunoBiologicals, Lisle, IL), glucose $(0.1 \%)$, and $20 \mathrm{~L}$ amino acids (11). The BSA was previously dialyzed against an approximate fivefold excess of buffer without albumin (three changes over $48 \mathrm{hr}$ at $4^{\circ} \mathrm{C}$ with shaking). The perfusing medium was aerated with humidified $\mathrm{O}_{2}: \mathrm{CO}_{2}$ $(95: 5)$ as it passed through a multibulb glass oxygenator and back into the glass reservoir; oxygenation occurred for $\geq 1 \mathrm{hr}$ prior to arterial cannulation and throughout the length of the experiment. Perfusate $p \mathrm{H}$ was monitored with a $\Phi 61 p \mathrm{H}$ meter (Beckman Instruments, Inc., Fullerton, CA) and adjusted, if necessary, to 7.4 .

\section{Surgical Procedure}

The rat IPK experiments were modeled after the methods described by Nishiitsutsuji-Uwo et al. (12) and Bowman (13). Male Sprague-Dawley rats 
$(310-410 \mathrm{~g})$ were anesthetized intraperitoneally with sodium pentobarbital $(50 \mathrm{mg} / \mathrm{kg}$ body weight). The left superficial femoral vein was exposed and $100 \mathrm{mg}$ of mannitol and 200 units of heparin were administered. A midline incision was made and the major abdominal vessels were isolated. A ligature was passed around the right renal artery, and proximal and distal ligatures were placed around the mesenteric artery. The right ureter was catheterized with PE-10 polyethylene tubing. The right renal artery was cannulated via the mesenteric artery and the hemostat holding back the perfusate was released upon entering the renal artery. The whole kidney was then excised, trimmed of adhering tissue, and transferred immediately to a recirculating perfusion apparatus, enclosed in a temperature-controlled $\left(37^{\circ} \mathrm{C}\right)$ Plexiglas chamber. Perfusion pressure in the renal artery was controlled by monitoring the manometer and adjusting the flow-pressure valve according. A correction was made for the intrinsic apparatus pressure.

\section{Experimental Design}

Angiotensin II (AII), a biologically active octapeptide, is one of the most powerful constrictors of vascular smooth muscle known. As such, AII served as a probe to study the effect of changes in perfusate flow rate (organ perfusion) on the renal clearance parameters of chlorothiazide in the rat IPK due to its direct vasoconstriction of afferent and efferent arterioles in the kidney (14-16).

Chlorothiazide $(3.08 \mathrm{mg} / \mathrm{ml})$ was dissolved in KHB buffer with the aid of $4 \mathrm{~N} \mathrm{NaOH}$, and $\left[{ }^{14} \mathrm{C}\right]$ inulin $(16.7 \mu \mathrm{Ci} / \mathrm{ml}$; specific activity, $2.0 \mu \mathrm{Ci} / \mathrm{mg}$; ICN Radiochemicals, Irvine, CA) was dissolved in distilled water. After a 15 -min equilibration period, $3.25 \mathrm{ml}$ of drug and $0.15 \mathrm{ml}$ of inulin were introduced as a bolus into the recirculating perfusate; initial perfusate concentrations of chlorothiazide were $100 \mu \mathrm{g} / \mathrm{ml}$. In those experiments containing AII (dissolved in normal saline), the peptide was introduced into the reservoir as a $1-4 \mathrm{ng} / \mathrm{min}$ constant-rate infusion $(0.0065-0.026 \mathrm{ml} / \mathrm{min})$, thereby allowing titration of the desired hemodynamic effect. An additional $15 \mathrm{~min}$ were then allowed for drug distribution to occur and for the pressure and flow to stabilize within normal physiological limits. The infusion rate of AII and the flow-pressure valve were adjusted empirically during the perfusion so as to produce a desired reduction in perfusion flow rate while maintaining consistent and viable kidney function. The subsequent time was divided into eight to ten 10-min urine collection periods for the measurement of kidney function and drug disposition parameters. The urine volume was measured with a tuberculin syringe and the $p \mathrm{H}$ was determined immediately. Perfusate $(1.5 \mathrm{ml})$ was sampled at the midpoint of each urine collection. Isovolumetric replacement of urine loss with buffer and perfusate sampling 
loss with blank perfusate was performed in order to minimize changes in perfusate composition during the experiment.

Functionality of the rat IPK was assessed primarily by measuring glomerular filtration rate $(G F R)$, the fractional excretion of glucose $\left(F E_{\text {glucose }}\right)$, and the fractional excretion of sodium $\left(F E_{\text {sodium }}\right)$. The renal clearance of inulin was taken to represent $G F R$. The renal clearances of chlorothiazide and inulin were calculated by dividing the urinary excretion rate of the substance by its perfusate concentration at the midpoint time interval. Chlorothiazide $(n=5)$ and control experiments (no drug present; $n=3$ ) were performed in the absence and presence of AII in the perfusate.

\section{Analytical Methods}

Perfusate and urine samples containing chlorothiazide were analyzed by adopting the reversed-phase, high-performance liquid chromatographic assay by Lin and Benet (17). Radioactive measurements for $\left[{ }^{14} \mathrm{C}\right]$ inulin were performed on an LS 3801 liquid scintillation counter (Beckman Instruments, Fullerton, CA) using an external standard method for quench correction. Glucose was determined with a YSI Model 27 Industrial Analyzer (Fisher Scientific, Chicago, IL) which utilizes an immobilized enzyme membrane mounted on the end of an electrochemical sensor, and sodium was determined with a model 455 flame photometer (Corning Medical and Scientific, Medfield, MA).

\section{Protein Binding}

The binding of chlorothiazide to albumin in the recirculating perfusate was determined using 1-ml acrylic plastic dialysis cells (10). One-half milliliter of perfusate was dialyzed against an equal volume of isotonic phosphate buffer (0.067 M, $p \mathrm{H} 7.4$ ) in a Dubnoff Metabolic Shaking Incubator (VWR Scientific, Chicago, IL) at $37^{\circ} \mathrm{C}$ for $7 \mathrm{hr}$ using Spectrapor 2 membrane tubing (Spectrum Medical Industries, Los Angeles, CA). Drug content in the dialyzed perfusate and buffer was then assayed by high-performance liquid chromatography, as described above.

No evidence of nonlinear protein binding was observed in any of the perfusion experiments. Therefore, the percentage of unbound chlorothiazide in the recirculating perfusate was calculated as (18)

$$
\% \text { Unbound }=\frac{100 \cdot C f^{\prime}}{C b^{\prime \prime}+C f^{\prime}}
$$

where $C f^{\prime}$ represents the measured unbound concentration of drug in buffer after dialysis, and $C b^{\prime \prime}$ represents the volume-corrected bound concentration 
of drug in the postdialysis perfusate. Values for $\mathrm{Cb}^{\prime \prime}$ were determined using the following equation:

$$
C b^{\prime \prime}=\frac{V p^{\prime} \cdot\left(C p^{\prime}-C f^{\prime}\right)}{V p}
$$

$V p^{\prime}$ and $V p$ represent the volumes of the perfusate compartment after and before dialysis, respectively, and $C p^{\prime}$ represents the measured total concentration of drug in perfusate after dialysis.

\section{Renal Transport Model}

In general, the excretion rate of a drug from the plasma into the urine is expressed by

$$
U \cdot V=\left[G F R \cdot C f+\frac{V_{\max } \cdot C f}{K_{\mathrm{m}}+C f}\right] \cdot(1-F)
$$

where $U$ is the drug concentration in urine, $V$ is the urine flow rate, GFR is the glomerular filtration rate, $C f$ is the unbound drug concentration in perfusate, $V_{\max }$ is the maximum velocity of secretion, $K_{\mathrm{m}}$ is the substrate concentration at which secretion proceeds at one-half its maximum velocity, and $F$ is the fraction of filtered and secreted drug that is reabsorbed.

If reabsorption does not occur $(F=0)$ and the renal transport processes are corrected for changes in functional nephron mass, the corrected urinary excretion rate can be expressed by the hyperbolic model

$$
\frac{U \cdot V}{G F R}=\left[C f+\frac{\left(V_{\mathrm{max}} / G F R\right) \cdot C f}{K_{\mathrm{m}}+C f}\right]
$$

\section{Data Analysis}

Transport data for chlorothiazide were fit to Eq. (4) using the nonlinear least-squares regression program MINSQ (19). The parameter estimates $( \pm$ SD) were obtained using a weighting factor of unity. The quality of fit was determined by evaluating the coefficient of determination, the standard deviation of parameter estimates and data, and by the visual inspection of residuals. Statistical differences between experimental groups for the physiological or clearance parameters were determined by a two-sample $t$ test. A $P$ value $\leq 0.05$ was considered significant.

\section{RESULTS}

\section{Physiological Function of the Perfused Kidney}

Control studies (no chlorothiazide) were initiated to evaluate the functional viability of the rat IPK under normal and reduced organ perfusions 
Table I. Effect of Angiotensin II on the Physiological Function of the Isolated Perfused Rat Kidney in the Absence of Chlorothiazide

\begin{tabular}{lccc}
\hline \multicolumn{1}{c}{ Parameter } & Without $\mathrm{AII}^{a}$ & ${\text { With } \mathrm{AII}^{b}}^{b}$ & $P$ \\
\hline Perfusion pressure $(\mathrm{mm} \mathrm{Hg})$ & $80.3 \pm 3.1$ & $95.3 \pm 0.6$ & $<0.002$ \\
Perfusate flow $(\mathrm{ml} / \mathrm{min})$ & $41.8 \pm 5.4$ & $24.1 \pm 0.2$ & $<0.005$ \\
$G F R(\mathrm{ml} / \mathrm{min})$ & $0.807 \pm 0.171$ & $0.795 \pm 0.102$ & $\mathrm{~ns}$ \\
$F E_{\text {qlucose }}(\%)$ & $4.30 \pm 1.84$ & $4.36 \pm 1.28$ & $\mathrm{~ns}$ \\
$F E_{\text {sodium }}(\%)$ & $10.1 \pm 1.6$ & $7.27 \pm 1.66$ & $\mathrm{~ns}$ \\
$F F(\%)$ & $1.94 \pm 0.40$ & $3.30 \pm 0.44$ & $<0.02$ \\
Urine flow $(\mathrm{ml} / \mathrm{min})$ & $0.145 \pm 0.014$ & $0.109 \pm 0.015$ & $<0.05$ \\
Urine $p \mathrm{H}$ & $6.33 \pm 0.085$ & $6.33 \pm 0.000$ & $\mathrm{~ns}$ \\
\hline
\end{tabular}

${ }^{a}$ Data reported as the $\bar{x} \pm$ SD of three perfusion experiments in which angiotensin was absent from the perfusate. Each perfusion consists of ten 10-min urine collection periods.

${ }^{b}$ Data reported as the $\vec{x} \pm \mathrm{SD}$ of three perfusion experiments in which angiotensin was present in the perfusate (infusion rate $=1-4 \mathrm{ng} / \mathrm{min}$ ). Each perfusion consists of ten 10-min urine collection periods.

(Table I). Even though greater pressures were observed in the group containing AII, perfusate flow rate could be reduced by $42 \%$ with no change in $G F R, F E_{\text {glucose }}$, or $F E_{\text {sodium }}$. As a result, the filtration fraction $(F F)$ was increased $70 \%$. Urine $p \mathrm{H}$ was stable during both treatments although urine flow tended to be reduced somewhat $(25 \%)$ in those studies with AII present. Quantitatively similar trends were observed in the physiological function of the rat IPK when chlorothiazide was present and organ perfusion was perturbed (Table II). Angiotensin induced a dramatic effect on the renal hemodynamics, resulting in a $43 \%$ reduction in perfusate flow and a $45 \%$ increase in filtration fraction. A small but significant decrease in $G F R$ was observed

Table II. Effect of Angiotensin II on the Physiological Function of the Isolated Perfused Rat Kidney in the Presence of Chlorothiazide ${ }^{a}$

\begin{tabular}{lccc}
\hline \multicolumn{1}{c}{ Parameter } & Without $\mathrm{AIl}^{h}$ & With $\mathrm{AII}^{c}$ & $P$ \\
\hline Perfusion pressure $(\mathrm{mm} \mathrm{Hg})$ & $84.2 \pm 8.4$ & $97.2 \pm 0.8$ & $<0.01$ \\
Perfusate flow $(\mathrm{ml} / \mathrm{min})$ & $41.6 \pm 6.7$ & $23.6 \pm 0.9$ & $<0.001$ \\
$G F R(\mathrm{ml} / \mathrm{min})$ & $0.850 \pm 0.075$ & $0.710 \pm 0.065$ & $<0.02$ \\
$F E_{\text {glucose }}(\%)$ & $4.18 \pm 1.77$ & $5.20 \pm 1.83$ & $\mathrm{~ns}$ \\
$F E_{\text {sodium }}(\%)$ & $14.8 \pm 2.5$ & $15.6 \pm 2.6$ & $\mathrm{~ns}$ \\
$F F(\%)$ & $2.07 \pm 0.26$ & $3.00 \pm 0.21$ & $<0.001$ \\
Urine flow $(\mathrm{ml} / \mathrm{min})$ & $0.147 \pm 0.013$ & $0.144 \pm 0.017$ & $\mathrm{~ns}$ \\
Urine $p \mathrm{H}$ & $6.52 \pm 0.17$ & $6.49 \pm 0.08$ & $\mathrm{~ns}$ \\
\hline
\end{tabular}

"Chlorothiazide was introduced to the perfusate at an initial concentration of $100 \mu \mathrm{g} / \mathrm{ml}$.

${ }^{b}$ Data reported as the $\bar{x} \pm \mathrm{SD}$ of five perfusion experiments in which angiotensin was absent from the perfusate. Each perfusion consists of eight to ten 10-min urine collection periods.

'Data reported as the $\tilde{x} \pm \mathrm{SD}$ of five perfusion experiments in which angiotensin was present in the perfusate (infusion rate $=1-4 \mathrm{ng} / \mathrm{min}$ ). Each perfusion consists of ten 10-min urine collection periods. 
(16\%) with no change in $F E_{\text {glucose }}$ and $F E_{\text {sodium }}$. Urine $p \mathrm{H}$ and urine flow were both stable in these two experimental groups.

\section{Chlorothiazide Excretion}

The effect of AII on the protein binding and renal clearance parameters of chlorothiazide are reported in Table III. As observed, the renal $\left(C L_{\mathrm{r}}\right)$ and secretory $\left(C L_{s}\right)$ clearances were reduced by $50 \%$ under conditions of reduced perfusate flow (AII present). This substantial decrease could not be explained by alterations in protein binding since the percentage of unbound chlorothiazide was not different between treatments. However, small differences in GFR could account for some of the variability in clearance parameters. When the renal clearance of chlorothiazide was corrected for the unbound fraction $(f u)$ and $G F R$, the excretion ratio $(E R)$ was reduced by $38 \%$ in the presence of AII. Still, these comparisons assume that linear kinetics are obeyed. This proved not to be the case for chlorothiazide transport and, as a result, more complex models were necessary.

Experimental data were fit to Eq. (4) to characterize the relationship between the corrected urinary excretion rates and unbound concentrations of chlorothiazide in the rat IPK (Figs. 1 and 2). Using the input values $U \cdot V /$ $G F R$ and $C f$, the transport parameters $V_{\max } / G F R$ and $K_{\mathrm{m}}$ were obtained for chlorothiazide in the absence and presence of AII (Table IV). As observed, the $V_{\max } / G F R$ (or $V_{\max }$ ) of chlorothiazide was $15-38 \%$ greater, on average, in the AlI study group. In contrast, the $K_{\mathrm{m}}$ of chlorothiazide was $133 \%$ greater, on average, in the presence of AII. As a result, the corrected intrinsic secretory clearance of chlorothiazide $\left[\left(V_{\max } / G F R\right) / K_{\mathrm{m}}\right]$ was substantially reduced $(41 \%)$ when the rat PIK was subjected to reduced perfusate flow.

It should be appreciated that the reabsorption fraction, $F$, was assumed to equal zero in order to simplify the data analyses. This is a reasonable

Table III. Effect of Angiotensin II on the Protein Binding and Clearance Parameters of Chlorothiazide in the Isolated Perfused Rat Kidney

\begin{tabular}{lccc}
\hline \multicolumn{1}{c}{ Parameter } & Without $\mathrm{All}^{a}$ & With $\mathrm{AII}^{b}$ & $P$ \\
\hline Unbound $(\%)$ & $6.23 \pm 0.43$ & $6.04 \pm 0.53$ & $\mathrm{~ns}$ \\
$C L_{\mathrm{r}}(\mathrm{ml} / \mathrm{min})$ & $4.62 \pm 0.57$ & $2.32 \pm 0.28$ & $<0.001$ \\
$C L_{\mathrm{s}}{ }^{c}(\mathrm{ml} / \mathrm{min})$ & $4.57 \pm 0.56$ & $2.28 \pm 0.28$ & $<0.001$ \\
$E R^{d}$ & $88.0 \pm 4.1$ & $54.8 \pm 7.9$ & $<0.001$ \\
\hline
\end{tabular}

"Data reported as the $\bar{x} \pm \mathrm{SD}$ of five perfusion experiments in which angiotensin was absent from the perfusate. Each perfusion consists of eight to ten 10-min urine collection periods.

${ }^{b}$ Data reported as the $\bar{x} \pm S D$ of five perfusion experiments in which angiotensin was present in the perfusate (infusion rate $=1-4 \mathrm{ng} / \mathrm{min}$ ). Each perfusion consists of ten 10-min urine collection periods.

${ }^{\prime} C L_{\mathrm{s}}=C L_{\mathrm{r}}-f u \cdot G F R$.

${ }^{d} E R=C L_{\mathrm{r}} /(f u \cdot G F R)$. 


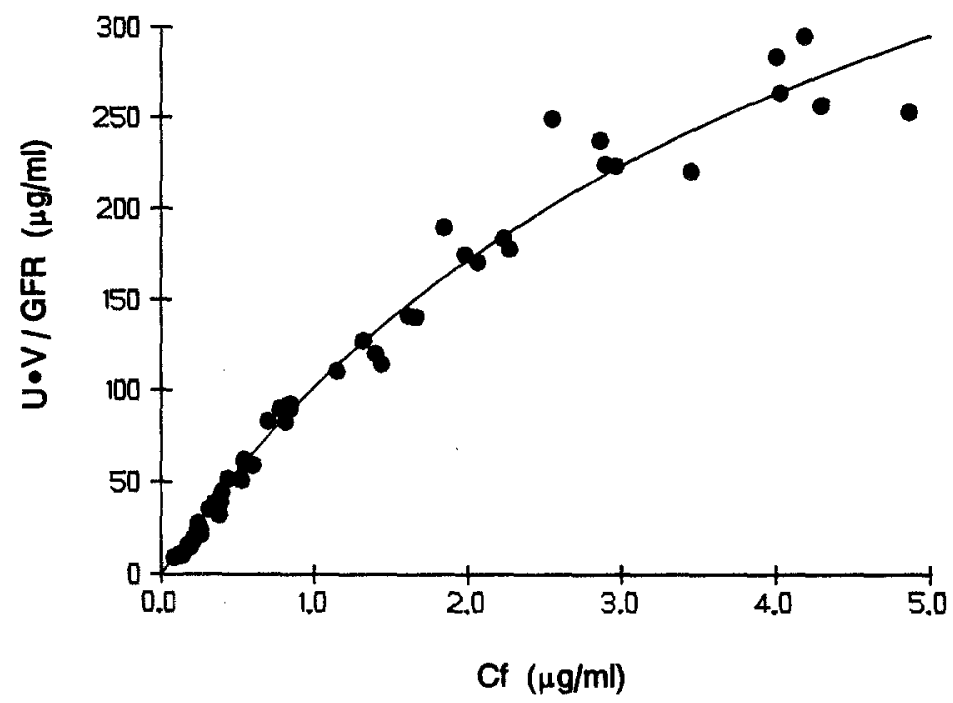

Fig. 1. Relationship between excretion rate corrected for $G F R(U \cdot V / G F R)$ and unbound concentration ( $C f$ ) of chlorothiazide in the rat IPK in the absence of AII. All 48 data points from five experiments are depicted. The solid line represents the computer-simulated curve based on the fitted parameters of Eq. (4).

assumption given the predominance of secretion in the renal elimination of chlorothiazide. However, if reabsorption does occur, the numerical value of $F$ is probably quite similar between experiments and would not affect the conclusions of the study. Constancy of reabsorption (if present) is likely because urine flow and $p \mathrm{H}$ were essentially equivalent between treatment groups, and because the variability of these two parameters was small $(C V<16 \%)$ between each perfusion experiment.

\section{DISCUSSION}

Cardiac failure can result in a variety of pathophysiological disturbances to the kidney (4). These might include a reduced and/or redistributed renal blood flow, tissue hypoxia, and visceral congestion. As a result, the intrinsic ability of the kidney to eliminate drug may be compromised, although a paucity of experimental data are available to support this correlation. For example, previous studies have reported that changes in organ perfusion rate may alter the renal and secretory clearances of furosemide in a significant manner (20-22). Although suggestive, these studies were limited in that renal blood flow measurements were performed in only one of the 


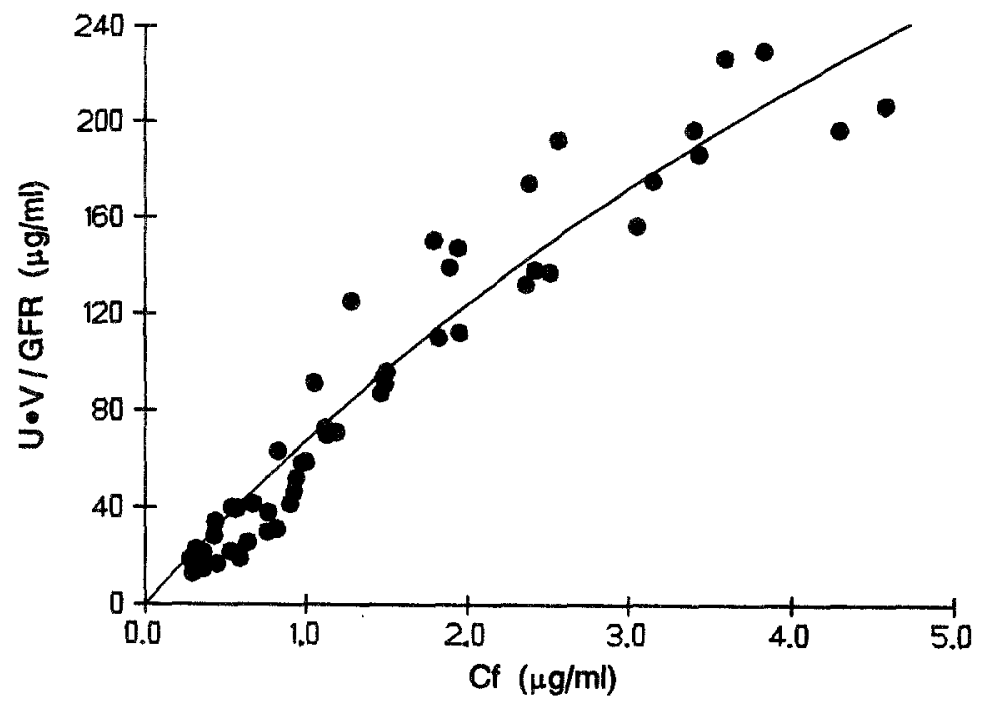

Fig. 2. Relationship between excretion rate corrected for $G F R(U \cdot V / G F R)$ and unbound concentration $(C f)$ of chlorothiazide in the rat IPK in the presence of AII. All 50 data points from five experiments are depicted. The solid line represents the computer-simulated curve based on the fitted parameters of Eq. (4).

Table IV. Renal Transport Parameters of Chlorothiazide in the Isolated Perfused Rat Kidney ${ }^{a}$

\begin{tabular}{cccccc}
\hline Study group & $\begin{array}{c}V_{\max } / G F R \\
(\mu \mathrm{g} / \mathrm{ml})\end{array}$ & $\begin{array}{c}K_{\mathrm{m}} \\
(\mu \mathrm{g} / \mathrm{ml})\end{array}$ & $\begin{array}{c}V_{\max }^{b} \\
(\mu \mathrm{g} / \mathrm{min})\end{array}$ & $\begin{array}{c}\left(V_{\max } / G F R\right) / \\
K_{\mathrm{m}} c^{2}\end{array}$ & $r^{2 d}$ \\
\hline Chlorothiazide alone & $539( \pm 41)$ & $4.37( \pm 0.54)$ & $458( \pm 54)$ & $123( \pm 18)$ & 0.978 \\
Chlorothiazide + All & $743( \pm 190)$ & $10.2( \pm 3.3)$ & $528( \pm 143)$ & $72.8( \pm 30.0)$ & 0.927 \\
\hline
\end{tabular}

${ }^{a}$ Data are reported as parameter estimates $( \pm \mathrm{SD})$.

${ }^{b} V_{\max }$ was calculated as the product of $V_{\max } / G F R$ and the mean value for $G F R$ in each study group.

${ }^{c}\left(V_{\max } / G F R\right) / K_{\mathrm{m}}$ was calculated as the quotient of $V_{\max } / G F R$ and $K_{\mathrm{m}}$ in each study group.

$d_{r}{ }^{2}$ is the coefficient of determination.

studies. In addition, the effect of changes in protein binding as well as kidney functionality were not considered in the treatment of the data. There is also evidence to suggest that vasodilator therapy, which resulted in the improved renal hemodynamics of congestive heart failure patients, can increase the intrinsic tubular secretion of digoxin (23). In this study, both nitroprusside and hydralazine were able to significantly increase the digoxin renal clearance without changing GFR. However, these changes were inconsistent. While nitroprusside administration resulted in a $36 \%$ increase in digoxin $C L_{\mathrm{r}} / G F R$ and a $36 \%$ increase in renal blood flow, hydralazine administration resulted in only a $21 \%$ increase in digoxin $C L_{\mathrm{r}} / G F R$ when renal blood 
flow was increased by $124 \%$. Furthermore, the use of a nonspecific radioimmunoassay along with a possible competition between digoxin and $p$ aminohippurate for secretory sites makes it difficult to interpret the data unambiguously.

For a compound of high renal extraction (and $F=0$ ), where the ability of the excretory organ to secrete the drug is much larger than the rate of drug delivery to the renal tubule, the secretory clearance approaches the flow rate $(Q)$ of plasma perfusing the renal tubular secretion sites (1).

$$
C L_{\mathrm{s}} \approx Q
$$

If the compound is also highly protein bound, then $C L_{\mathrm{r}} \approx C L_{\mathrm{s}}$. Given this relationship, it is obvious that changes in organ perfusion should cause significant if not proportional changes in the renal and secretory clearances of this compound. However, an attenuated perfusion flow rate could not explain the reduced clearance parameters of chlorothiazide in the present study since this drug is one of low renal extraction in the rat IPK (10); in vivo, the renal clearance of chlorothiazide approaches that of renal plasma flow.

For a drug that is highly protein bound and of low renal extraction (and $F=0$ ), the ability of the excretory organ to secrete the drug is much smaller than the rate of drug delivery to the renal tubule, and

$$
\begin{gathered}
C L_{\mathrm{r}}=f u \cdot G F R+f u \cdot K_{\mathrm{s}} \\
C L_{\mathrm{r}} \approx C L_{\mathrm{s}}=f u \cdot K_{\mathrm{s}}
\end{gathered}
$$

where $K_{\mathrm{s}}$ is the intrinsic renal tubular secretion clearance of unbound drug (equivalent to $V_{\max } / K_{\mathrm{m}}$ ). The excretion ratio $(E R)$ can then be calculated by dividing the $C L_{\mathrm{r}}$ by $f u \cdot G F R$.

$$
E R=1+\frac{K_{\mathrm{s}}}{G F R}
$$

Analysis of Eqs. (7) and (8) reveal that $C L_{\mathrm{r}}$ and $E R$ should not be affected by changes in organ perfusion unless, as a result, the functional nephron mass or efficiency of tubular secretion per unit nephron, respectively, is altered. As shown in Table IV, it appears that the reduced intrinsic secretory transport of chlorothiazide reflects an inefficiency of transport (i.e., larger value for $K_{\mathrm{m}}$ ) as opposed to a reduced number of transport sites (i.e., $V_{\max } /$ $G F R$ or $V_{\text {max }}$ ). Although speculative, the observed reduction in perfusion flow rate may have been accompanied by a redistribution of flow within the kidney, tissue hypoxia, or congestion and, thereby, result in disturbed organ function. Alternatively, these transport changes may be the result of a direct 
tubular effect of AII on the transporter itself. In this regard, separate experiments that can determine the direct influence of AII on tubular drug transport in the absence of a flow effect (e.g., vesicle studies) will be necessary. Pressure changes are an unlikely mechanism for the reduction in chlorothiazide secretion since only a modest increase in pressure is observed in this treatment group (chlorothiazide + AIl). Similar reductions in secretory clearance were also observed for furosemide and cefonicid in rat IPK experiments in which AII caused dramatic hemodynamic changes but pressure was unchanged $(5,24)$.

In control and perfusion studies with chlorothiazide, it is evident that AII had no significant effects on functional nephron mass $(G F R)$ and proximal tubular transport per nephron $\left(F E_{\text {glucose }}\right)$. Although larger values are observed for $F E_{\text {sodium }}$, as compared to $F E_{\text {glucose }}$, these values are not unusual and probably reflect the selective damage of distal nephrons during the perfusion experiments (25-27). Still, the proximal tubule retains considerable capacity for transport, as evidenced by the relatively low and consistent values for $F E_{\text {glucose }}$ in all study groups.

A number of low perfusion flow preparations have also been described in the literature $(28,29)$. Using a recirculating perfusate enriched with bovine erythrocytes, a significant improvement in tubular sodium handling and concentrating ability of the rat IPK occurs as compared to a conventional cell-free medium. However, the preparations using hematocrits of $20-25 \%$ and $40-45 \%$ also show a $G F R$ that is $30-40 \%$ lower than in kidneys with $0 \%$ hematocrit, and appear to be unstable in that GFR decreases $32 \%$ on average over a 90 -min perfusion period. More recently, kidney viability data were reported in a recirculating (constant pressure) and single-pass (constant flow) red blood cell-perfused rat kidney with hematocrits of $17 \%$ (30). In these recirculating perfusions, kidney function was well-maintained over a limited study period of $50 \mathrm{~min}$ and the blood perfusate flow rate was $14.4 \mathrm{ml} /$ min per g kidney weight. In the present study with chlorothiazide, perfusate flows were approximately 17 and $30 \mathrm{ml} / \mathrm{min}$ per g kidney weight in the presence and absence of AII.

Chlorothiazide is a sulfonamide diuretic that inhibits active solute transport primarily in the cortical thick ascending limb of Henle (31). As a result, the values for $F E_{\text {sodium }}$ were increased by $62 \%$ in chlorothiazide vs. control perfusions with no AII $(P=0.063)$, and by $100 \%$ in chlorothiazide vs. control perfusions with AII $(P<0.002)$. The lack of diuretic effect in these experiments is consistent with those reported previously in the rat IPK with chlorothiazide (10), and may reflect the inability to dilute/concentrate the urine in the distal nephron (32). Because of functional abnormalities in this tubular region, a word of caution is advised in studying drug dynamics in nephron segments beyond the proximal tubule. 
In summary, this study demonstrates that alterations in organ perfusion can significantly reduce the clearance parameters of chlorothiazide in the rat IPK. These flow-induced changes in intrinsic secretory transport may reflect perturbations other than that of perfusion flow rate alone.

\section{ACKNOWLEDGMENTS}

The authors thank Bradley W. Shinn and James Welch for their help with the experimental setup and data collection aspects of the study.

\section{REFERENCES}

1. G. Levy. Effect of plasma protein binding on renal clearance of drugs. J. Pharm. Sci. 69:482-483 (1980).

2. S. Øie and L. Z. Benet. Altered drug disposition in disease states. Ann. Rep. Med. Chem. 15:277-287 (1980).

3. G. R. Wilkinson. Clearance approaches in pharmacology. Pharmacol. Rev. 39:1-47 (1987).

4. N. L. Benowitz. Effects of cardiac disease on pharmacokinetics: Pathophysiologic considerations. In L. Z. Benet, N. Massoud, and J. G. Gambertoglio (eds.), Pharmacokinetic Basis for Drug Treatment, Raven, New York, 1984, pp. 89-103.

5. L.-J. Lee and D. E. Smith. Effect of organ perfusion on renal drug transport: Application to furosemide in the isolated perfused rat kidney. Drug Metab. Dispos. 17:32-36 (1989).

6. C. A. M. van Ginneken and F. G. M. Russel. Saturable pharmacokinetics in the renal excretion of drugs. Clin. Pharmacokin. 16:38-54 (1989).

7. D. C. Brater and P. Chennavasin. Effects of renal disease: Pharmacokinetic considerations. In L. Z. Benet, N. Massoud, and J. G. Gambertoglio (eds.), Pharmacokinetic Basis for Drug Treatment, Raven, New York, 1984, pp. 119-147.

8. L. Z. Benet and L. B. Sheiner. Design and optimization of dosage regimens: Pharmacokinetic data. In A. G. Gilman, L. S. Goodman, T. W. Rall, and F. Murad (eds.), The Pharmacological Basis of Therapeutics, 7th ed., Macmillan, New York, 1985, p. 1678.

9. H. R. Brettell, J. K. Aikawa, and G. S. Gordon. Studies with chlorothiazide tagged with radioactive carbon $\left(\mathrm{C}^{14}\right)$ in human beings. Arch. Intern. Med. 106:57-63 (1960).

10. L.-J. Lee, J. A. Cook, and D. E. Smith. Renal transport kinetics of chlorothiazide in the isolated perfused rat kidney. J. Pharmacol. Exp. Ther. 247:203-208 (1988).

11. F. H. Epstein, J. T. Brosnan, J. D. Tange, and B. D. Ross. Improved function with amino acids in the isolated perfused kidney. Am. J. Physiol. 243:F284-F292 (1982).

12. J. M. Nishiitsutsuji-Uwo, B. D. Ross, and H. A. Krebs. Metabolic activities of the isolated perfused rat kidney. Biochem. J. 103:852-862 (1967).

13. R. H. Bowman. The perfused rat kidney. Meth. Enzymol. 39:3-11 (1975).

14. W. W. Douglas. Polypeptides-angiotensin, plasma kinins, and others. In A. G. Gilman, L. S. Goodman, T. W. Rall, and F. Murad (eds.), The Pharmacological Basis of Therapeutics, 7th ed., Macmillan, New York, 1985, pp. 639-659.

15. A. C. Guyton. In Textbook of Medical Plysiology, 5th ed., W. B. Saunders, Philadelphia, 1976 , pp. $469-470$.

16. E. K. Jackson, R. A. Branch, H. S. Margolius, and J. A. Oates. Physiological functions of the renal prostaglandin, renin, and kallikrein systems. In D. W. Seldin and G. Giebisch (eds.), The Kidney: Physiology and Pathophysiology, Vol. 1, Raven, New York, 1985, pp. 613-644.

17. E. T. Lin and L. Z. Benet. High pressure liquid chromatographic determination of chlorothiazide and hydrochlorothiazide in human serum and urine. APhA Acad. Pharm. Sci. 8(1):194 (1978). 
18. T. N. Tozer, J. G. Gambertoglio, D. E. Furst, D. S. Avery, and N. H. G. Holford. Volume shifts and protein binding estimates using equilibrium dialysis: Application to prednisolone binding in humans. J. Pharm. Sci. 72:1442-1446 (1983),

19. MINSQ: Nonlinear parameter estimation and model development, MicroMath Scientific Software, Salt Lake City, UT, 1988.

20. F. Andreasen and E. Mikkelsen. Distribution, elimination and effect of furosemide in normal subjects and in patients with heart failure. Eur. J. Clin. Pharmacol. 12:15-22 (1977).

21. R. Babini and P. J. Du Souich. Furosemide pharmacodynamics: Effect of respiratory and acid-base disturbances. J. Pharmacol. Exp. Ther. 237:623-628 (1986).

22. D. C. Brater, R. Seiwell, S. Anderson, A. Burdette, G. J. Dehmer, and P. Chennavasin. Absorption and disposition of furosemide in congestive heart failure. Kidney Int. 22:171176 (1982).

23. J. J. Cogan, M. H. Humphreys, C. J. Carlson, N. L. Benowitz, and E. Rapaport. Acute vasodilator therapy increases renal clearance of digoxin in patients with congestive heart failure. Circulation 64:973-976 (1981).

24. C. A. Rodriguez and D. E. Smith. Influence of angiotensin IL-induced alterations in renal flow on excretion of cefonicid in isolated perfused rat kidneys. Antimicrob. Agents Chemother. 36:616-619 (1992).

25. D. Alcorn, K. R. Emslie, B. D. Ross, G. B. Ryan, and J. D. Tange. Selective distal nephron damage during isolated kidney perfusion. Kidney Int. 19:638-647 (1981).

26. M. Brezis, S. Rosen, P. Silva, and F. H. Epstein. Selective vulnerability of the medullary thick ascending limb to anoxia in the isolated perfused rat kidney. J. Clin. Invest. 73:182-190 (1984).

27. M. Brezis, S. Rosen, P. Silva, and F. H. Epstein. Transport activity modifies thick ascending limb damage in the isolated perfused kidney. Kidney Int. 25:65-72 (1984).

28. W. Lieberthal, G. W. Stephens, E. F. Wolf, H. G. Rennke, M. L. Vasilevsky, C. R. Valeri, and N. G. Levinsky. Effect of erythrocytes on the function and morphology of the isolated perfused rat kidney. Renal Physiol. 10:14-24 (1987).

29. W. Lieberthal, M. L. Vasilevsky, C. R. Valeri, and N. G. Levinsky. Interactions between ADH and prostaglandins in isolated erythrocyte-perfused rat kidney. Am. J. Physiol. 252:F331-F337 (1987).

30. 1. A. M. De Lannoy, R. Nespeca, and K. S. Pang. Renal handling of enalapril and enalaprilat: Studies in the isolated red blood cell-perfused rat kidney. J. Pharmacol. Exp. Ther. 251:1211-1222 (1989).

31. H. R. Jacobson and J. P. Kokko. Diuretics: Sites and mechanisms of action. Ann. Rev. Pharmacol. Toxicol. 16:201-214 (1976).

32. T. Maack. Physiological evaluation of the isolated perfused rat kidney. Am. J. Physiol. 238:F71-F78 (1980). 